\title{
Biosynthesis of Pyridoxine in Saccharomyces cerevisiae -Origin of the Pyridoxine Nitrogen Atom Differs under Anaerobic and Aerobic Conditions-
}

\author{
Shiho IsHIDA and Kazuko YAMADA \\ School of Pharmaceutical Sciences, Mukogawa Women's University, \\ 11-68 Koshien Kyuban-cho, Nishinomiya, Hyogo 663-8179, Japan
}

(Received July 10, 2002)

\begin{abstract}
Summary The amide nitrogen atom of glutamine is incorporated into pyridoxine in four eukaryotes (i.e., Emericella nidulans, Mucor racemosus, Neurospora crassa and Saccharomyces cerevisiae) and two prokaryotes (i.e., Staphylococcus aureus and Bacillus subtilis). However, in the prokaryotes Pseudomonas putida, Enterobacter aerogenes and Escherichia coli, it is the nitrogen atom of glutamate that is incorporated into pyridoxine (J Nutr Sci Vitaminol (2000) 46, 55-57). As these results were from experiments conducted under aerobic conditions, we investigated the biosynthesis of pyridoxine on S. cerevisiae under anaerobic conditions. The results showed that [amide- $\left.{ }^{15} \mathrm{~N}\right] \mathrm{L}$-glutamine was not incorporated into pyridoxine, unlike the results for aerobic conditions. The incorporation of $\left[{ }^{15} \mathrm{~N}\right] \mathrm{ammonium}$ salts into pyridoxine was not inhibited in the presence of casamino acids and tryptophan. The results showed that the nitrogen atoms of amino acids are not used for the biosynthesis of pyridoxine. The incorporation of ${ }^{15} \mathrm{~N}$ into pyridoxine was inhibited in the presence of adenine, but not in that of hypoxanthine. Thus, the nitrogen atom of pyridoxine may be from the amino group attached to the $C-6$ of adenine.
\end{abstract}

Key Words vitamin $\mathrm{B}_{6}$, pyridoxine, biosynthesis, adenine, anaerobic conditions

The biosynthetic pathway of pyridoxine has been studied by many researchers. In 1990, Lam and Winkler proposed, based on a gene analysis of Escherichia coli, that pyridoxine is synthesized from 1deoxy-D-xylulose and 4-hydroxy-L-threonine, and that $p d x A$ and $p d x J$ are involved in the biosynthesis (1). Spenser and co-workers showed that the labels of $[2,3-$ $\left.{ }^{13} \mathrm{C}_{2}\right]$-1-deoxy-D-xylulose and $\left[2,3-{ }^{13} \mathrm{C}_{2}\right]-4$-hydroxy-Lthreonine were incorporated into $\mathrm{C}-2$ and $\mathrm{C}-3$ and $\mathrm{C}-6$ and $C-5$ of pyridoxine, respectively, in E. coli $(2,3)$. Cane et al. reported that, in the last stage of pyridoxine biosynthesis in E. coli, $p d x A$ and $p d x J$ are expressed and clarified these enzymatic mechanisms (4).

We have studied the origin of the pyridoxine nitrogen atom and reported that there are at least two biosynthetic pathways (5). In E. coli, the amino nitrogen of glutamate is incorporated into pyridoxine, while in $S$. cerevisiae, the amide nitrogen atom of glutamine is incorporated. The amide nitrogen atom of glutamine is also incorporated into pyridoxine in four eukaryotes (i.e., Emericella nidulans, Mucor racemosus, Neurospora crassa and Saccharomyces cerevisiae) and two prokaryotes (i.e., Staphylococcus aureus and Bacillus subtilis). However, in the following three prokaryotes, Pseudomonas putida, Enterobacter aerogenes and E. coli, it is the nitrogen atom of glutamate that is incorporated into pyridoxine (6).

In 1999, Ehrenshaft et al. (7) and Osmani et al. (8)

E-mail: ishiho@mwu.mukogawa-u.ac.jp studied the distribution of SOR1 (pyroA) in eukaryotes and prokaryotes and compared the results with those for the genes of $p d x A / J$ found in $E$. coli. They reported that plants, fungi and archaebacteria have SOR1, but some eubacteria have SOR1 while others have $p d x A / J$.

In $S$. cerevisiae, the carbon skeleton of pyridoxine remains to be clarified. When we reported that the pyrimidine moiety of thiamin consists of histidine and pyridoxine, we proposed that 5-phosphoribosyl-1-amine is incorporated into $\mathrm{N}-1, \mathrm{C}-6, \mathrm{C}-5$, and $\mathrm{C}-5^{\prime}$ of pyridoxine and the moiety is transferred into $\mathrm{N}-1, \mathrm{C}-6, \mathrm{C}-5$, and C$5^{\prime}$ of the pyrimidine (9). We described the unresolved precursor of the carbon skeleton as being a unit of five carbons, C-2', C-2, C-3, C-4, and C-4'.

Spenser and his coworkers showed that the precursor of $\mathrm{C}-2^{\prime}$ to $\mathrm{C}-4^{\prime}$ unit of pyridoxine was not 1-deoxyxylulose in S. cerevisiae and proposed that the C-1, C-2, C-3, $\mathrm{C}-4$, and $\mathrm{C}-5$ of ribose or ribulose are incorporated into the $\mathrm{C}-2^{\prime}, \mathrm{C}-2, \mathrm{C}-3, \mathrm{C}-4$, and $\mathrm{C}-4^{\prime}$ of pyridoxine (10). This result indicates that the last precursor of pyridoxine is $2^{\prime}$-hydroxypyridoxine (11).

These experiments were done under aerobic conditions. As the use of anaerobic conditions may influence the results, we studied the biosynthesis of pyridoxine on $S$. cerevisiae under such conditions. Our results revealed a different origin of the pyridoxine nitrogen atom in $S$. cerevisiae under anaerobic conditions.

\section{MATERIALS AND METHODS}

Materials. $\quad\left[{ }^{15} \mathrm{~N}\right]$ Ammonium chloride $\left(99{ }^{15} \mathrm{~N}\right.$ atom 
$\%$ ) and $\left[{ }^{15} \mathrm{~N}_{2}\right]$ ammonium sulfate were purchased from Shoko Co., Ltd. (Tokyo, Japan), [amide- $\left.{ }^{15} \mathrm{~N}\right] \mathrm{L}$-glutamine $\left(99{ }^{15} \mathrm{~N}\right.$ atom \%) was purchased from Cambridge Isotope Laboratories (MA, USA), and $\left[{ }^{15} \mathrm{~N}\right] \mathrm{L}$-glutamic acid $\left(99{ }^{15} \mathrm{~N}\right.$ atom \%) was purchased from ICON Services Inc. (NY, USA). Casamino acids were vitaminfree products from Difco Laboratories (MI, USA). All other chemicals were of analytical grade.

Growth conditions. S. cerevisiae IFO 1234 was grown in synthetic media under the anaerobic conditions described previously (12). The nitrogen sources of the media were substituted with $\left[{ }^{15} \mathrm{~N}\right]$ ammonium chloride $(0.5 \mathrm{~g} / \mathrm{L})$ and $\left[{ }^{15} \mathrm{~N}_{2}\right]$ ammonium sulfate $(0.5 \mathrm{~g} / \mathrm{L})$ for tracer experiments. Casamino acids $(2.0 \mathrm{~g} / \mathrm{L})$ and tryptophan $(0.1 \mathrm{~g} / \mathrm{L})$ were added as competitors, as were uracil, adenine, and hypoxanthine at $3 \mathrm{~mm}$ concentrations. S. cerevisiae was grown at $30^{\circ} \mathrm{C}$ for $15 \mathrm{~h}$ under anaerobic conditions. During this period, S. cerevisiae increased to about three times its original amount, respectively.

Isolation and analysis of pyridoxine from $S$. cerevisiae. The isolation of pyridoxine from $S$. cerevisiae and its acetylation and analysis by GC-MS have been described elsewhere $(5,6)$.

\section{RESULTS AND DISCUSSION}

The mass spectrum of authentic acetylpyridoxine has been presented in a previous report (5). The analysis of pyridoxine fragmentation was based on the report by DeJongh and Korytnyk (13). The molecular ion $\left[\mathrm{M}^{+}\right]$ (i.e., $m / z 295$ ), fragment ions (i.e., $m / z 253,235$, and 193), and the base peak at $m / z 151$ have a nitrogen atom from the pyridine ring.

Incorporation of [amide- $\left.{ }^{15} \mathrm{~N}\right] \mathrm{L}$-glutamine and $\left[{ }^{15} \mathrm{~N}\right] \mathrm{L}$-glutamate into pyridoxine

As we have reported previously, the label of [amide$\left.{ }^{15} \mathrm{~N}\right] \mathrm{L}$-glutamine was incorporated into pyridoxine in $S$. cerevisiae under aerobic conditions (5). However, as can be seen by the comparison in Fig. 1A, under anaerobic conditions, [amide- ${ }^{15} \mathrm{~N}$ ]L-glutamine was not incorporated into pyridoxine (Fig. 1B), suggesting that the origin of pyridoxine nitrogen is different in yeast under aerobic and anaerobic conditions.

Under aerobic conditions, the origin of the nitrogen atom in E. coli was the nitrogen atom of glutamate (6). Using the same conditions, but in anaerobic state, the nitrogen atom of glutamate was studied using $S$. cerevisiae. The nitrogen of glutamate was also not incorporated into pyridoxine under anaerobic conditions.

Under aerobic conditions, the origin of the pyridoxine nitrogen atom is the amide- $\mathrm{N}$ of glutamine in S. cerevisiae, while under anaerobic conditions, the amide- $\mathrm{N}$ of glutamine and the N-atom of glutamate were not incorporated into pyridoxine. Thus, $S$. cerevisiae seems to have a different biosynthetic pathway for pyridoxine under anaerobic conditions as compared to aerobic conditions. We studied the origin of the pyridoxine nitrogen atom under anaerobic conditions in S. cerevisiae.
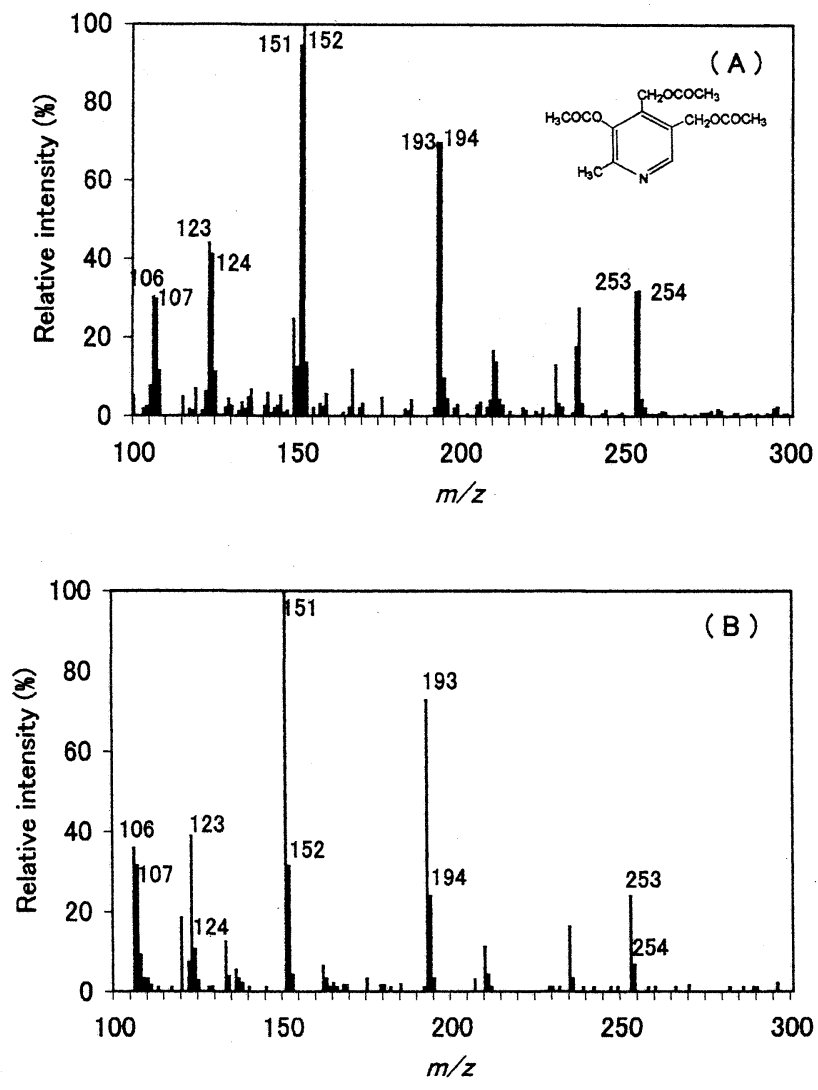

Fig. 1. Mass spectrum of acetylpyridoxine derived from pyridoxine produced by $S$. cerevisiae in the presence of [amide- $\left.{ }^{15} \mathrm{~N}\right] \mathrm{L}$-glutamine under aerobic conditions (A) and anaerobic conditions (B). Under anaerobic conditions, OD values before and after the growth of $S$. cerevisiae were 0.139 and 0.523 , respectively. The pyridoxine, produced by $S$. cerevisiae and purified, was acetylated by the addition of $1 \mathrm{~mL}$ of acetic anhydride/pyridine ( $1: 1)$ solution. Details of the analysis of acetylpyridoxine are described in the text.

\section{Amino acids as the possible precursor of the $N$ atom of pyri-} doxine

To find the origin of pyridoxine nitrogen under aerobic conditions, we conducted an experiment incorporating the ${ }^{15} \mathrm{~N}$ atoms of $\left[{ }^{15} \mathrm{~N}\right]$ ammonium chloride and $\left[{ }^{15} \mathrm{~N}_{2}\right]$ ammonium sulfate into pyridoxine (Fig. 2). The competitive effect of casamino acids and tryptophan is shown in Fig. 3. The relative intensity of acethylpyridoxine was the same as that in its MS spectrum in the absence of amino acids, showing that the origin of the pyridoxine nitrogen atom under anaerobic conditions is not the nitrogen of amino acids.

Inhibition of ${ }^{15} \mathrm{~N}$ incorporation into pyridoxine by nucleobases (adenine and uracil)

As amino acids were not the precursors of pyridoxine, we studied the adenine and uracil nucleobases (Figs. 4 and 5). There was no inhibition of incorporation with uracil. The addition of adenine inhibited the incorporation of ${ }^{15} \mathrm{~N}$ into pyridoxine because the peaks of $m / z 151,106,123$, and 193 increased as compared to the Ms spectrum of Fig. 2, suggesting that one of the nitrogen atoms of adenine was incorporated into pyridoxine. 


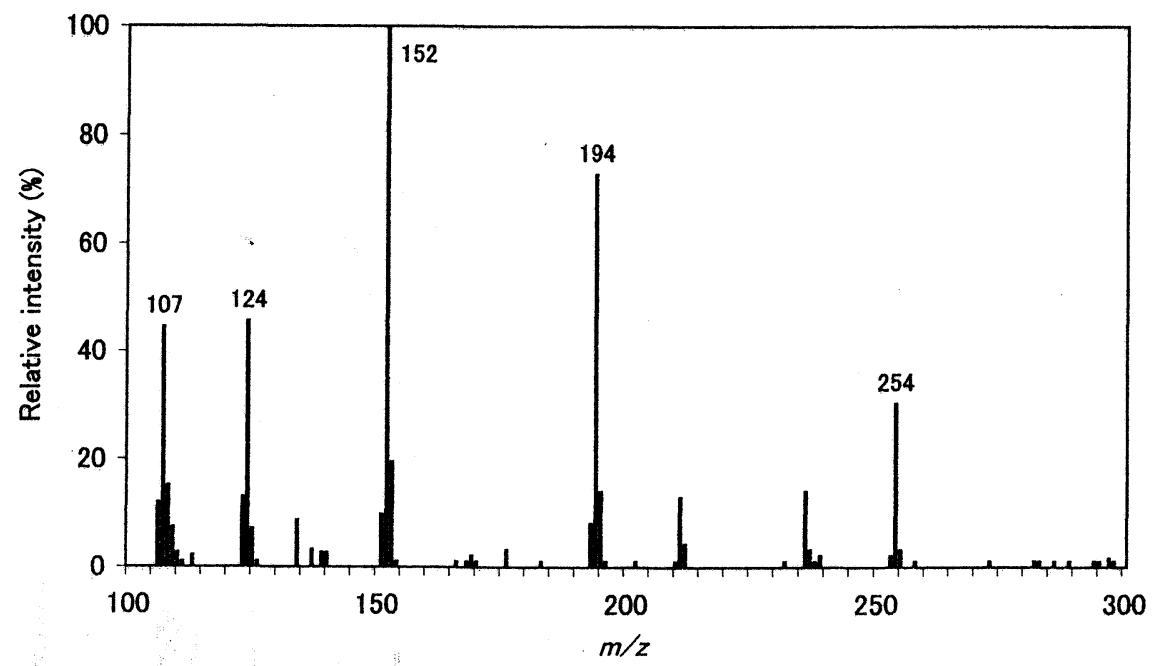

Fig. 2. Mass spectrum of the acetylpyridoxine produced by $S$. cerevisiae in the presence of $\left[{ }^{15} \mathrm{~N}\right]$ ammonium chloride and $\left[{ }^{15} \mathrm{~N}_{2}\right]$ ammonium sulfate as nitrogen sources under anaerobic conditions. OD values before and after the growth of $S$. cerevisiae were 0.119 and 0.412 , respectively.

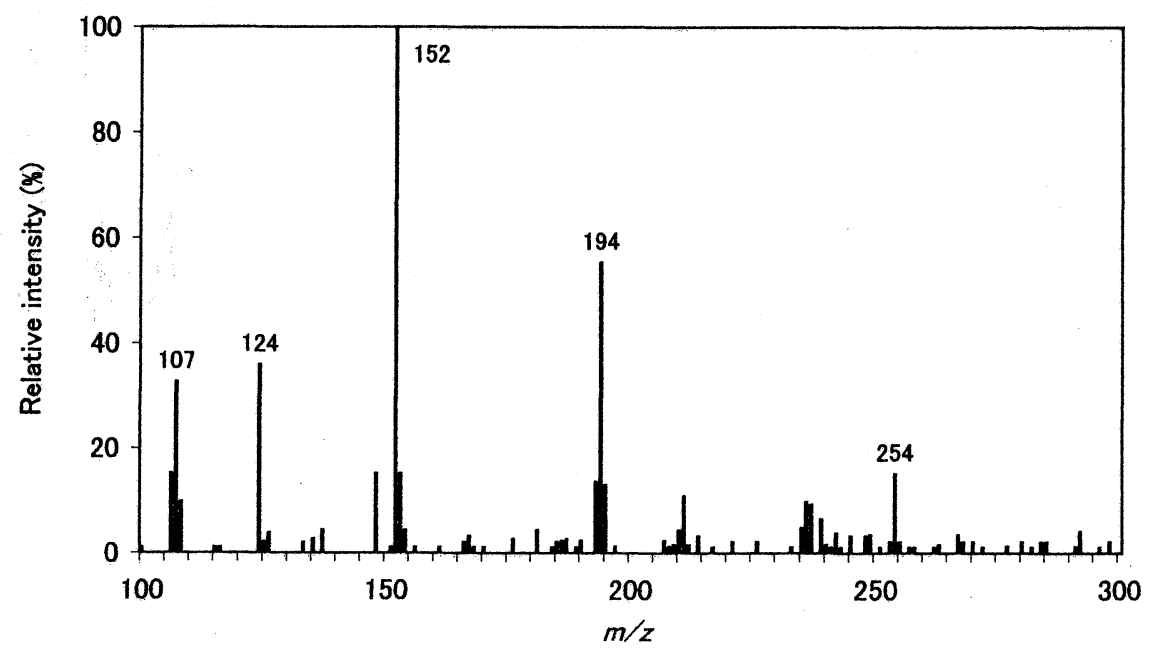

Fig. 3. Inhibition of $\left[{ }^{15} \mathrm{~N}\right]$ incorporation of $\left[{ }^{15} \mathrm{~N}\right]$ ammonium salts in the presence of casamino acids and L-tryptophan under anaerobic conditions. OD values before and after the growth of $S$. cerevisiae were 0.133 and 0.315 , respectively.

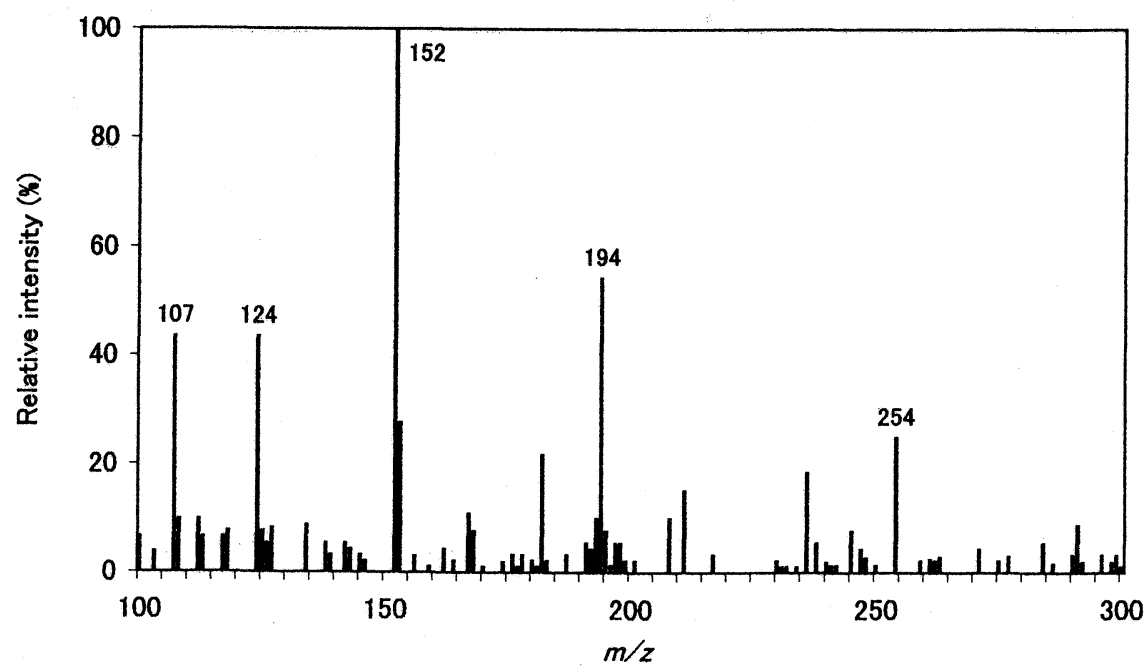

Fig. 4. Inhibition of $\left[{ }^{15} \mathrm{~N}\right]$ incorporation from $\left[{ }^{15} \mathrm{~N}\right]$ ammonium salts into pyridoxine in the presence of uracil under anaerobic conditions. OD values before and after the growth of $S$. cerevisiae were 0.112 and 0.398 , respectively. 


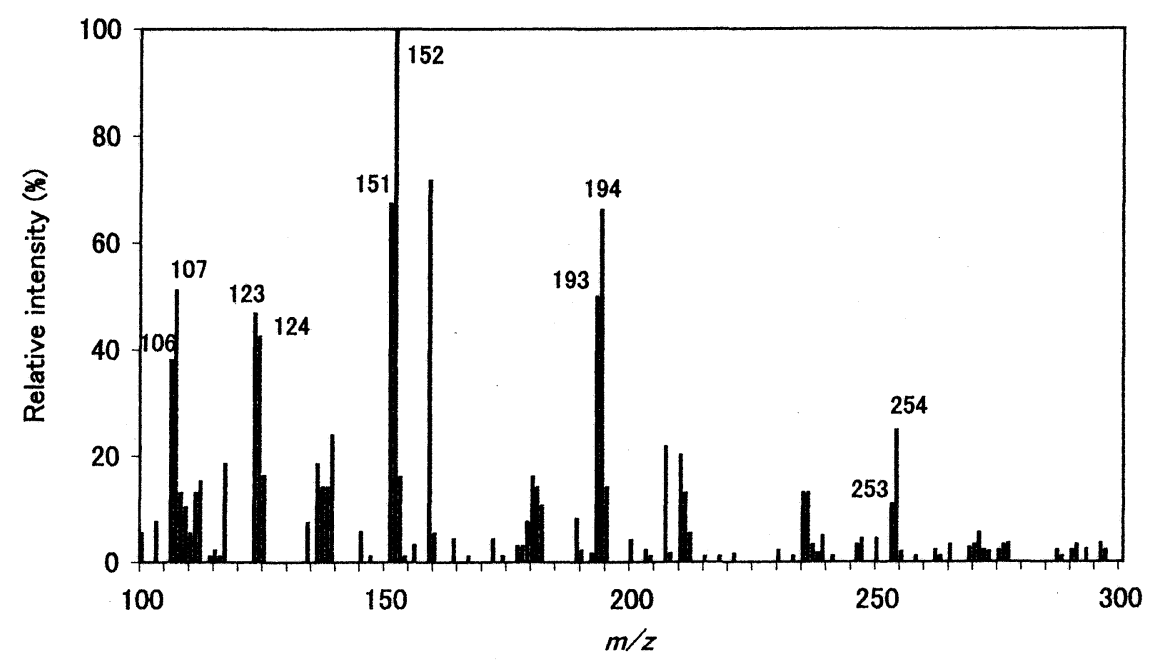

Fig. 5. Inhibition of $\left[{ }^{15} \mathrm{~N}\right]$ incorporation from $\left[{ }^{15} \mathrm{~N}\right]$ ammonium salts into pyridoxine in the presence of adenine under anaerobic conditions. OD values before and after the growth of $S$. cerevisiae were 0.112 and 0.343 , respectively.

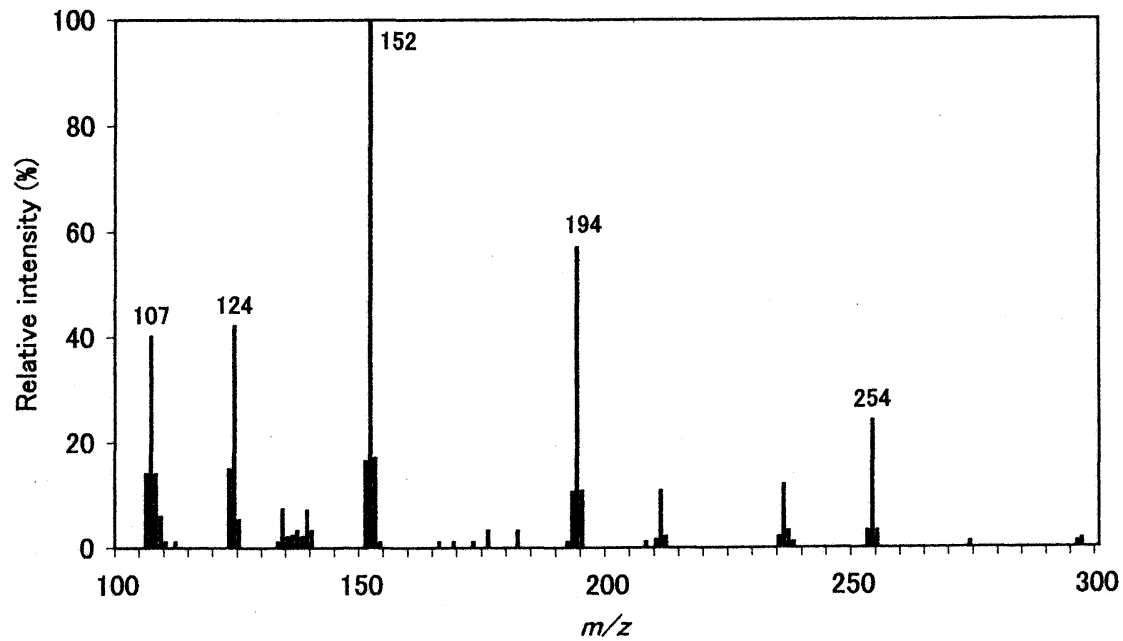

Fig. 6. Inhibition of $\left[{ }^{15} \mathrm{~N}\right]$ incorporation from $\left[{ }^{15} \mathrm{~N}\right]$ ammonium salts into pyridoxine in the presence of hypoxanthine under anaerobic conditions. OD values before and after the growth of $S$. cerevisiae were 0.108 and 0.407 , respectively.

\section{Inhibition of ${ }^{15} \mathrm{~N}$ incorporation by hypoxanthine}

As a nitrogen atom of adenine was incorporated into pyridoxine, we studied whether or not the amino group attached to the C-6 of adenine was the origin of the pyridoxine. Hypoxanthine, which does not have an amino group attached to C-6, was used as a competitor for the incorporation of ${ }^{15} \mathrm{~N}$. As shown in Fig. 6, the incorporation of ${ }^{15} \mathrm{~N}$ was not inhibited by hypoxanthine if the origin of the pyridoxine nitrogen was the amino group attached to the C- 6 of adenine.

Our finding that the origin of the pyridoxine nitrogen atom is from the amino group attached to the C- 6 of adenine under anaerobic conditions was supported by the results that the incorporation of $\left[{ }^{15} \mathrm{~N}\right] \mathrm{ammonium}$ salts into pyridoxine was inhibited by adenine, but not by hypoxanthine.

The biosynthetic pathway is clearly different between some bacteria and eukaryotes as described in the introduction. The question remains about whether the origin of the pyridoxine nitrogen atom differs among species under anaerobic conditions.

\section{REFERENCES}

1) Lam H, Winkler ME. 1990. Metabolic relationship between pyridoxine and serine biosynthesis in Escherichia coli K-12. J Bacteriol 172: 6518-6528.

2) Wolf E, Spenser ID. 1995. $\left[2,3-{ }^{13} C_{2}\right]-4$-Hydroxy-L-threonine. J Org Chem 60: 6937-6940.

3) Kennedy IA, Hill RE, Pauloski RE, Sayer BG, Spenser ID. 1995. Biosynthesis of vitamin $B_{6}$. Origin of pyridoxine by the union of two acyclic precursors, 1-deoxy-D-xylulose and 4-hydroxy-L-threonine. J Am Chem Soc 117: 1661-1662.

4) Cane DE, Du S, Robinson JK, Hsiung Y, Spenser ID. 1999. Biosynthesis of vitamin $\mathrm{B}_{6}$ : Enzymatic conversion of 1-deoxy-D-xylulose-5-phosphate to pyridoxol phosphate. J Am Chem Soc 121: 7722-7723.

5) Tazuya K, Adachi Y, Masuda K, Yamada K, Kumaoka H. 1995. Origin of the nitrogen atom of pyridoxine in Saccharomyces cerevisiae. Biochim Biophys Acta 1244: 113-116.

6) Tanaka K, Tazuya K, Yamada K, Kumaoka H. 2000. Biosynthesis of pyridoxine origin of nitrogen atom of pyridoxine in microorganisms. J Nutr Sci Vitaminol 46: 
55-57.

7) Ehrenshaft M, Bilski P, Li MY, Chignell CF, Daub ME. 1999. A highly conserved sequence is a novel gene involved in de novo vitamin $\mathrm{B}_{6}$ biosynthesis. Proc Natl Acad Sci USA 96: 9374-9378.

8) Osmani AH, May GS, Osmani SA. 1999. The extremely conserved proA gene of Aspergillus nidulans is required for pyridoxine synthesis and is required indirectly for resistance to photosensitizers. I Biol Chem 274: 23565-23569.

9) Tazuya K, Yamada K, Kumaoka H. 1993. Pyridoxine is a precursor of the pyrimidine moiety of thiamin in Saccharomyces cerevisiae. Biochem Mol Biol Int 30: 893-899.
10) Gupta RN, Hemscheidt T, Sayer BG, Spenser ID. 2001. Biosynthesis of vitamin $\mathrm{B}_{6}$ in yeast: Incorporation pattern of glucose. J Am Chem Soc 123: 11353-11359.

11) Zeidler J, Ullah N, Gupta RN, Pauloski RM, Sayer BG, Spenser ID. 2002. 2'Hydroxypyridoxol, a biosynthesis precursor of vitamin $\mathrm{B}_{6}$ and $\mathrm{B}_{1}$ in yeast. J Am Chem Soc 124: 4542-4543.

12) Tanaka K, Tazuya K, Yamada K, Kumaoka H. 2000. Biosynthesis of thiamin under anaerobic conditions in Saccharomyces cerevisiae. Biol Pharm Bull 23: 108-111.

13) DeJongh DC, Korytnyk W. 1970. Mass spectrometry of vitamin $\mathrm{B}_{6}$. In: Vitamins and Coenzymes (McCormick DB, Wright LB, eds), Methods in Enzymology, Vol 18, part A, p 483-494. Academic Press, Inc., New York. 